\title{
Critical Incident Analysis in Measurement of Hotel Guest Satisfaction. A Case Study from Tirana, Albania
}

\author{
Majlinda Godolja \\ University of Tirana \\ Email: majlinda.godolja@unitir.edu.al
}

Doi:10.5901/jesr.2014.v4n4p437

\author{
Alma Spaho \\ University of Tirana \\ Email: alma.spaho@unitir.edu.al
}

\section{Abstract}

\begin{abstract}
Services sector continues to be the big contributor in GDP of Albania, with about $60 \%$ in 2011, where trade, hotels and restorants constitute the main part of this sector. Number of hotels is increased during the last years. In 1995, the number of hotels was 62 with 2,016 beds places, whereas in 2012 the number of hotels was 248 with 18,905 beds places (INSTAT). To be successful in the market it is not sufficient to attract new customers, hotel managers must concentrate on retaining existing guests implementing effective policies of customer satisfaction. The best products in all aspects of product services not necessarily provide the best quality of services. The hotel managers need to constantly monitor the guest needs that are changeable, in order to facilitate their analysis and ensure the effective management of change in the performance of the hotel product. The aim of this study is to evaluate hotel guest satisfaction based on the critical incident analysis (Hayes 2008) and determining the extent to which the quality of hotel services meets customer needs and preferences. The research was conducted in 3- star hotels in Tirana, Albania. The data are collected in 10 mid-range hotels in the period July - August 2013. Through the analysis of this case we evaluate the overall customer satisfaction level for the hotels and for each service supplied. The results obtained in this study indicate that the level of customer satisfaction is very good considering the overall evaluation but also the lower level than expected in terms of hotels facilities and Food \& Drink. The research results can be used by hotel managers in order to improve and adapt hotel services to customer needs.
\end{abstract}

Keywords: customer satisfaction, service quality, critical incident analysis, hotels, Tirana.

\section{Introduction}

Service quality and customer satisfaction have a significant impact on business development. Service quality has a direct impact on customer satisfaction, and consequently increases the profit. These two concepts have been continually in the focus of managers and researchers of the field. In order to achieve customer satisfaction, it is important to recognize and to anticipate customers' needs and to be able to satisfy them. Enterprises which are able to rapidly understand and satisfy customers' needs, make greater profits than those which fail to understand and satisfy them (Barsky \& Nash, 2003). One of the methods used for measuring customer satisfaction in hotels is Critical Incident Analysis. The Critical Incident Technique is a qualitative interview procedure which facilitates the investigation of significant occurrences (events, incidents, processes, or issues) identified by the respondent, the way they are managed, and the outcomes in terms of perceived effects. The objective is to gain understanding of the incident from the perspective of the individual, taking into account cognitive, affective, and behavioral elements. The purpose of this study is the evaluation of customer satisfaction in hotels of Tirana, Albania. In this study was used Critical Incident Analysis according to the recent applications of Critical Incident Technique in hospitality service. The strength of Critical Incident Analysis lies in its utilization of customers in defining customer requirements. Customers are in a good position to help the hotel management to understand these requirements because they are the recipients of the hotel services. The results of this study provide the hotel management staff, an evaluation of the current methods for measuring and managing customer satisfaction in hotels of Tirana, Albania. 


\section{Literature Review}

\subsection{Service quality and customer satisfaction}

The primary function of the hotel units is to offer quality service to its customers. Service quality is defined as how well customer's needs are met, and how well the service delivered meets the customer's expectations (Lewis and Booms, 1983). Gronoos (1984) has shown that the perceived quality of service is a function of the comparison of expected service with perceived service, in other words is the result of a comparative evaluation process. Parasuraman et al. (1985) has defined "quality of service" as the degree and direction of discrepancy between perceptions and expectations of their customers, where "perceived service quality" is the gap between customer's expectations and perceptions as a measurement of service quality. Smaller the gap, the better is the quality of service and greater customer satisfaction is.

\subsection{Measuring customer satisfaction}

The main reason for measuring customer satisfaction is to collect information from one side to see what customers require to be done differently and in turn to assess how client needs are met. However the reasons for measuring customer satisfaction differ from one hotel to another. Some of the hotels fail to properly pursue programs dedicated customers not only because they have not defined program to get feedback from customers, but because they lack a complete database which not only monitors sales but it is also a source of innovation.

According to literature customer satisfaction measurement is done in different ways, for example one of the ways is to include a single question in customer satisfaction questionnaire: "In general, how satisfied are you with...?" where responses of the questionnaire questions are made according to a system with 5 degrees from "very unsatisfied" (coded 1) to "very satisfied " (coded 5), known as Likert scale. Problems associated to the answer of one single question in this case, are mitigated by the simplicity of the question. (Heskett et al., 1994; Schneider and Bowen, 1995) have developed a theory for the measurement of customer satisfaction based on key elements of satisfaction in service and price, but their valuation is done independently through the "index service" and "price index".

\subsection{The Critical Incident Technique (CIT)}

Critical Incident Technique, a method that relies on a set of procedures to collect, content analyze and classify observations of human behavior, was first introduced to the social sciences by Flanagan (1954). Chell (1998) provided the following description of the CIT method: The critical incident technique is a qualitative interview procedure which facilitates the investigation of significant occurrences (events, incidents, processes, or issues) identified by the respondent, the way they are managed, and the outcomes in terms of perceived effects. The objective is to gain understanding of the incident from the perspective of the individual, taking into account cognitive, affective, and behavioral elements. A critical incident is described as one that makes a significant contribution, either positively or negatively, to an activity or phenomenon (Bitner and Booms, 1990; Grove and Fisk 1997). Critical incidents can be gathered in various ways, but in service sectors, the approach generally asks respondents to tell a story about an experience they have had. The CIT method provides a rich source of data by allowing respondents to determine which incidents are the most relevant to them for the phenomenon being investigated. The CIT is a research method that allows respondents as "free a range of responses" as possible within an overall research framework (Gabbott and Hogg 1996). With the CIT method, there is no preconception or idiosyncratic determination of what will be important to the respondent (de Ruyter, Perkins, and Wetzels 1995); so the context is developed entirely from the respondent's perspective (Chell 1998). The CIT method reflects the normal way service customers think (Stauss 1993) and does not force them into any given framework. During an interview, respondents are simply asked to recall specific events; they can use their own terms and language (Stauss and Weinlich 1997). Thus, CIT is an attractive method of investigation because it does not restrict observations to a limited set of variables or activities (Walker and Truly 1992).

A CIT study consists of 5 main steps ranging from the problem definition over the data collection to the analysis and interpretation of the results. The main idea is to ask a sample of respondents to address important aspects that they liked, and did not like, during the service production. By categorizing these so-called critical incidents and counting them out across the sample, the analyst obtains a list of important categories/attributes and over the relation between positive and negative comments in these attributes a performance evaluation

The CIT studies can be conducted to determine the factors that influence the customers' satisfaction. It is vague to define if the mentioned attributes whether evaluated as important or not, do really have influence on the satisfaction of the 
customer. However, according to Martilla and James (1977), every performance analysis should determine the decisive importance and performance aspects and use customer or professional interviews during its establishment. However, it can not be expected that the factors that lead to dissatisfaction, when they are not sufficiently met, were not determined.

\section{Research Methodology}

The target population of the study consists of hotel guests in 3, 4 and stars hotels in Tirana, Albania. During the period July - August 2013, a questionnaire was distributed to guests of 10 central mid-range hotels of Tirana, in order: 1) to identify which factors are important in developing customer satisfaction in hotels of Tirana, Albania, 2) to study the feedback of customers on these factors, 3 ) to identify factors on which customers are highly satisfied and dissatisfied, 4) based on this what recommends can be done for improvement.

Questionnaires were built in two parts. In the first part the clients are required to evaluate: Cleanliness, Comfort, Location, Facilities, Staff and Value for money, from 1 (below average) to 5 (excellent). In the second part with respect to critical incidents, we collected data on both positive and negative incidents. For positive incidents, we asked the respondent to think about the experience of staying in the hotel and to recall if there was any particular incident during this period which had made him or her particularly satisfied. If the answer was yes, the respondent was asked to provide a verbal account of this incident. In addition, we asked the respondent to assess the degree to which the selected incident was perceived as satisfying; the question was "How satisfied were you with that?", and we provided a response format with three steps comprising somewhat satisfied, satisfied, and very satisfied. The same approach was used to capture data about negative incidents, but in this case the question was "How dissatisfied were you with that?" and the three response alternatives were somewhat dissatisfied, dissatisfied, and very dissatisfied.

The questionnaire, together with a personal letter from the hotel managers and the researchers, were sent by email to the guests after they checked-out and were asked to fill the questionnaire and return the completed questionnaire by email. The response rate was about $62 \%$ and 104 questionnaires were collected.

\section{Results and Discussion}

Research results related to the average values and standard deviation are presented separately in table 1, for 3 and 4 star hotels. The overall service perception is very good, the hotel staff are the most, while comfort and facilities are the least valued. The overall assessment is better for the 4 star hotels, but the guests perceive more value for 3 star hotels. The standard deviation is low for evaluation of staff and value for money and it is higher valued for location and comfort in 3 star hotels. In 4 star hotels the standard deviation values are almost the same for all services and overall assessment.

Table 1.

\begin{tabular}{|c|l|c|c|c|c|c|c|c|}
\hline Hotels & & Overall & Cleanliness & Comfort & Location & Facilities & Staff & Value for money \\
\hline \multirow{2}{*}{ 3-star } & Mean & 4.242778 & 4.326667 & 3.96 & 4.376667 & 3.943333 & 4.486667 & 4.363333 \\
\cline { 2 - 9 } & Std. Deviation & 0.228508 & 0.275724 & 0.40541 & 0.450344 & 0.244121 & 0.174711 & 0.180739 \\
\hline \multirow{2}{*}{ 4-star } & Mean & 4.426042 & 4.242778 & 4.621875 & 4.453125 & 4.271875 & 4.5625 & 4.25 \\
\cline { 2 - 9 } & Std. Deviation & 0.280026 & 0.250977 & 0.260428 & 0.374374 & 0.2875 & 0.239792 & 0.267083 \\
\hline
\end{tabular}

Verbal expressions obtained have been first grouped by service related and then expressions are classified according to the judgment of the respondent. What emerges from the questionnaires is an overall positive customer satisfaction level. The main strengths of the hotels are: the staff and location; the weaknesses are the hotel facilities like parking, small rooms and bathrooms, limited number of restaurants, visible signs from the street etc... 
Table 2.

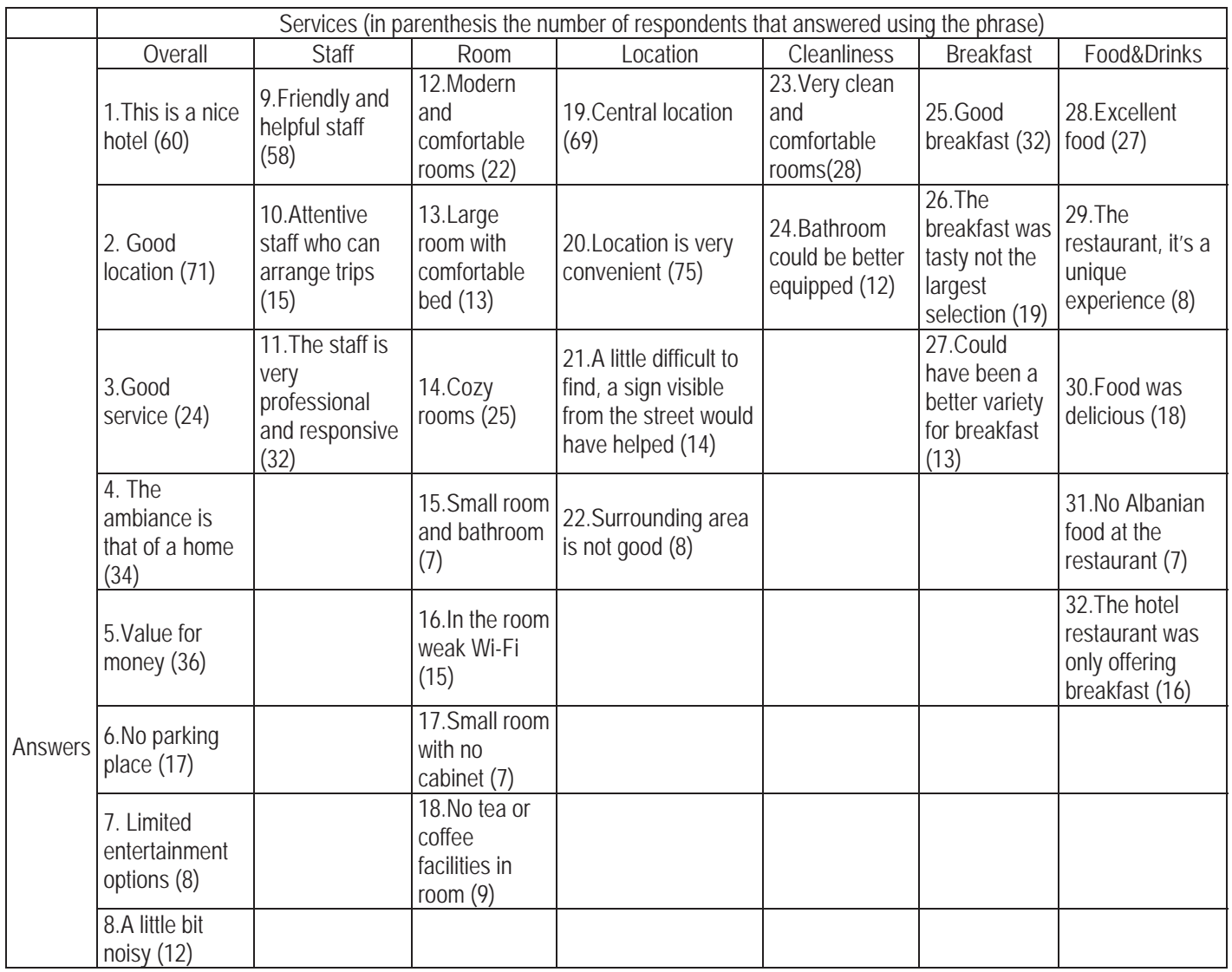

\begin{tabular}{|l|c|c|c|}
\hline \multicolumn{4}{|c|}{ Overall Service Perception } \\
\hline Judgment & Very satisfied & Satisfied & Somewhat satisfied \\
\hline Expressions & $1,2,3,4,5$ & $1,2,3,4,5$ & \\
\hline No. of Answers & $20,55,9,10,18$ & $40,16,15,24,18$ & \\
\hline
\end{tabular}

\begin{tabular}{|l|c|c|c|}
\hline \multicolumn{4}{|c|}{ Reception Service } \\
\hline Judgment & Very satisfied & Satisfied & Somewhat satisfied \\
\hline Expressions & $9,10,11$, & $9,10,11$ & \\
\hline No. of Answers & $42,6,11$ & $16,9,21$ & \\
\hline
\end{tabular}

\begin{tabular}{|l|c|c|c|}
\hline \multicolumn{4}{|c|}{ Room Quality } \\
\hline Judgment & Very satisfied & Satisfied & Somewhat satisfied \\
\hline Expressions & $12,13,14,23$ & $12,13,14,23$ & \\
\hline No. of Answers & & & \\
\hline
\end{tabular}

\begin{tabular}{|l|c|c|c|}
\hline \multicolumn{4}{|c|}{ Food \& Drink } \\
\hline Judgment & Very satisfied & Satisfied & Somewhat satisfied \\
\hline Expressions & $25,26,28,29,30$ & $25,26,28,29,30$ & \\
\hline No. of Answers & $12,17,10,8,15$ & $20,2,17,0,5$ & \\
\hline
\end{tabular}

\begin{tabular}{|l|c|c|c|}
\hline \multicolumn{4}{|c|}{ Dissatisfaction Incidents } \\
\hline Judgment & Very dissatisfied & Dissatisfied & Somewhat dissatisfied \\
\hline Expressions & & $6,7,8,15,16,17,18,21,22,24,27,31,32$ & $6,7,8,15,16,17,18,21,22,24,27,31,32$ \\
\hline No. of Answers & & $14,2,10,1,10,4,2,10,0,4,6,1,5$, & $3,6,2,6,5,3,7,4,8,8,7,6,11$ \\
\hline
\end{tabular}




\section{Conclusion}

The objective of this study was to find out the level of customers satisfaction with the services provided by hotels in Tirana using CIT method. The strength of Critical Incident Analysis lies in its utilization of customers in defining customer requirements. Customers are in a good position to help the hotel management to understand these requirements because they are the recipients of the hotel services.

The average score, of overall evaluation is very good. It means that in general, the hotels in Tirana are providing their customers with a good service and keeping service quality on a good level. The main strengths of the hotels are: the staff and location. The overall assessment is better for the 4 star hotels, but the guests perceive more value from 3 star hotels.

Despite of good feedback, there are some problems, which influence customer's satisfaction. The weaknesses are the hotel facilities like parking, small rooms and bathrooms, limited number of restaurants, better variety for breakfast, visible signs from the street etc...

The hotel business in Albania have to review the evaluation methods of customer satisfaction and service quality in order to be in compliance with all the best practices identified so far. Valid information and reliable data will enable hotel managers to make appropriate decisions about the quality of services that hotels offer.

\section{References}

Barsky, J., \& Nash, L. (2003). Customer satisfaction: Applying concepts to industry- wide measures. The Cornell Hotel and Restaurant Administration Quarterly, 44 (4): 173-183.

Bitner, Mary Jo, Booms, Bernard, H. \& Mohr, Lois, A. (1994). "Critical Service Encounters: The Employee's View," Journal of Marketing, 58 (October), 95-106

Chell, Elizabeth, \& Pittaway, Luke (1998). "A Study of Entrepreneurship in the Restaurant and Café Industry: Exploratory Work Using the Critical Incident Technique as a Methodology, "International Journal of Hospitality Management, 17, 23-32

De Ruyter, Ko, Kasper, Hans, \& Wetzels, Martin, (1995). "Internal Service Quality in a Manufacturing Firm: A Review of Critical Encounters", New Zealand Journal of Business, 17 (2), 67-80

Flanagan, J. C. (1954). "The Critical Incident Technique," Psychological Bulletin, Vol. 51, No. 4, pp. 327-359.

Gabbott, Mark, \& Hogg, Gillian, (1996). "The Glory of Stories: Using Critical Incidents to Understand Service Evaluation in the Primary Healthcare Context," Journal of Marketing Management, 12, 493-503

Grove, Stephen, J., \& Fisk, Raymond, P. (1997). "The Impact of Other Customers on Service Experiences: A Critical Incident Examination of 'Getting Along,' "Journal of Retailing, 73 (Spring), 63-85

Martilla, J. A., \& James, J. C. (1977). "Importance-Performance Analysis," Journal of Marketing, Vol. 41, No. 1, pp. 77-79.

Stauss, Bernd (1993), "Using the Critical Incident Technique in Measuring and Managing Service Quality," in The Service Quality Handbook, Eberhard E. Scheuing and William F. Christopher, eds. New York: American Management Association, 408-27.

Stauss, Weinlich, Bernhard (1997). "Process-Oriented Measurement of Service Quality: Applying the Sequential Incident Technique," European Journal of Marketing, 31 (1), 33-55

Walker, Steve, \& Truly, Elise, (1992). "The Critical Incidents Technique: Philosophical Foundations and Methodological Implications," in AMA Winter Educators'Conference Proceedings: Marketing Theory and Applications, Vol. 3, Allen, Chris, T. \& Madden, Thomas, J. eds. Chicago: American Marketing Association, 270-75 